\title{
Mi mamá, la cárcel y yo
}

\section{Luis A. Vergara Cisterna}

Abogado

"Ya visualizarán mi problema, la cárcel. Que aparece separándome de mi madre, como en el título de este escrito, y al mismo tiempo uniéndome a ella, por razón de la indigencia que padezco, no sólo en el plano material, sino además afectivo y filial.

Qué cosa más extraña que un niño menor de dos años, como vuestro servidor, considerado legalmente libre por la Constitución Política de la República, deba nacer en la cárcel y vivir allí para satisfacer su propio interés superior. De seguro que el Estado tiene una real justificación para esto y que el problema no se reduce a una falta de medios para asistirme socialmente en la comunidad, porque si así fuera, estaríamos diciendo que una criatura como yo, que tengo apenas a mi madre, sólo puede aspirar a vivir en la cárcel y que además debe sentirse satisfecho por ello, atendiendo que en esta reclusión tengo acceso a ciertas prestaciones sociales que en ninguna otra parte obtendré. Entonces, jsólo falta que me obliguen a declararme dichoso de estar en la cárcel y en una condición superior a todos aquellos que en un estado de indigencia similar se encuentran en libertad!

Disculpen, pero no entiendo cómo es que vivir en un recinto penitenciario resultó de mayor estándar. ¿O es que yo me siento preso y realmente no lo soy, y sólo comparto la cárcel con mi madre, pero soy un hombre libre, completamente libre?

Trataré de recordar esto, a pesar de los gendarmes, de la infraestructura, de las celdas, del vocabulario, del ambiente, de mis compañeros y de que ya me di cuenta que esto es una cárcel.

Qué problema el mío. Tal vez, la mencionada indigencia que aduzco, sea la verdadera causante de mis desvaríos. A lo mejor es mi falta de madurez la que me hace dudar de la legitimidad que tiene el sistema para violar mi derecho como hombre libre, haciéndome vivir la reclusión de mi madre, aduciendo como último fin mi propio bienestar. En otras palabras, haciéndome responsable de mi propia reclusión. Qué infamia. Sé que estoy equivocado, y que lo mío es sólo un problema filosófico para entender la reclusión y la libertad, y que zafado de este pensamiento crítico que me atormenta, podré por fin sentir que todo 
esto -vivir en la cárcel sin haber cometido siquiera delito- es algo bueno y querible, que aporta a mi existencia y que en nada contradice los postulados sacros del Estado de Derecho.

¡Cuánto me gustaría estar seguro de que este sentimiento es infundado y que sólo obedece a una falsa percepción que se ha apoderado de mí: de creer que a nadie le interesa lo que pienso, y a muy pocos lo que siento, victimizándome injustificadamente dada mi condición de pobre, iletrado e hijo de delincuente! Por más esfuerzo que hago no logro salir de este estadio de pensamiento.

Si me dijeran que existen otros, que en su calidad de adultos con carencias similares a las mias, se los encarcela para su bien, tal vez lograría una mayor tranquilidad. Pero según entiendo, no los hay. A los adultos sólo se les considera pobres, pero libres y aunque mueran por causa de su indigencia, el Estado no altera de ordinario su libertad, sino sólo los deja pobres y libres. O sea, no los mete a la cárcel para sobrellevar sus males.

Entonces, no entiendo: ¿Por qué a mí? ¿Porque estoy en formación y requiero de mi madre? Eso es todo.

¿Es decir la cercanía con ella borrará la cárcel? Tengo mis dudas.

Seguro que es falta de comprensión filosófica. La libertad es un problema de filosofía. ¿O no?

En mi corto entendimiento, veo con gran simpleza este aparente problema, y lo resumo de la siguiente forma: yo soy un sujeto de derechos que por mi edad y condición de madurez, no gozo de facultad alguna para conducirme en la vida y por ello debo ser asistido y proveído de todo cuanto necesite para lograr mi pleno desarrollo. Para esto, entiendo, subsidiariamente está el Estado: ente político que me protege, me quiere, me cuida y por sobre todas las cosas, está siempre a mi servicio, reconociéndome además como un hombre libre.

Por otro lado, está mi madre definida y condenada como delincuente, por este mismo Estado, que la resguarda y la obliga a cumplir con la pena que legítimamente le ha impuesto, privándola de libertad, introduciendo con ello la dificultad que intentamos dilucidar y que se traduce en cómo hacer compatible el castigo penal, sin afectar mis derechos, ni la relación que tengo con ella.

En el estado del relato, conviene dejar claro mi entender, y es que siendo yo el que requiere mayor cuidado, deben generarse a favor 
mío las condiciones adecuadas para mi desarrollo. O sea, darme la posibilidad de mantener un vínculo afectivo con aquella mujer que me ha parido, y ejerce el rol de madre, independiente de si ésta ha cometido o no delito. Sólo así puedo entender como verdadero el amor que me profesa el cuerpo político y sólo asi me he de sentir seguro y protegido por él.

Sin duda, esta solución excede con mucho lo que hoy día existe, y no es cuestionable esta afirmación, salvo que tú como lector, creas que las citadas condiciones adecuadas para mi desarrollo como niño, están en la cárcel o que peor aún, creas derechamente que la cárcel me ofrece las mejores condiciones para alcanzar ese desarrollo. Si así piensas, uno de los dos está equivocado. Yo, por pensar que bajo respecto alguno debo entrar a vivir en las prisiones, o tú, que opinas que "adentro" estoy mejor que "afuera," dada mi indigencia y vulnerabilidad, toda vez que allí gozo de bienes que en libertad no obtendré, y por cierto, atendida la posibilidad que allí tengo de compartir con mi madre que se encuentra presa sin poder salir.

Pero como podrías pensar siquiera, de la forma expuesta. ¡Sería una locura! Principalmente porque todas esas afirmaciones son falaces. ¡Claro! Lo que escuchas son embustes. Sí, porque si de prestaciones sociales se trata, estas mismas que se me brindan hoy en la cárcel pueden ser efectuadas en un centro comunitario, nada impide que así sea. Es más, el modelo político obliga a que se me asista en libertad: es ilógico, ilegítimo e ilegal que me tengan preso. Sin sentencia por lo demás.

Si el problema ahora es mi madre condenada, y la necesidad del vínculo con ella, que el Estado entonces asuma su rol de estar a mi servicio y le provea de un permiso para que me visite o para que conviva conmigo fuera de la cárcel. En otras palabras, que me valore como sujeto de derechos, y si realmente le importo, como pregona altisonantemente a los cuatro vientos, asuma el riesgo de fuga, sin privarme de vivir como un hombre libre. ¿Acaso no es este un derecho fundamental? Pero, qué sé yo, si simplemente soy un lactante encarcelado..."

La voz es ficticia. Pero no el problema. En Chile existen aproximadamente 42.222 menores de 18 años que tienen a lo menos uno de sus progenitores, padre o madre, privados de libertad $^{1}$ y con ello están afectos a una condición que incide significativamente en su desarrollo, con serias posibilidades de alta 
vulnerabilidad. De este total, 1.465 menores de dos años, durante el año $2008^{2}$ han sido insertos en el programa Residencias Transitorias, que de acuerdo a las bases técnicas establecidas en la Ley $\mathrm{N}^{\mathrm{o}} 20.032,{ }^{3}$ posibilitó generar un convenio, que tiene por objetivo "Promover y proteger el desarrollo físico, mental, social y emocional de los niños y niñas menores de 0 a 2 años de edad, que ingresan y permanecen junto a sus madres en los establecimientos penales del país, proporcionándoles un ambiente físico y humano que asegure su bienestar integral y fortalezca sus vínculos sociofamiliares." Este convenio suscrito entre Gendarmería de Chile ${ }^{4}$ y el Servicio Nacional de Menores, considera la entrega de una subvención mensual para 120 niños/as lactantes, que se atienden en Secciones Segmentadas, denominadas Materno-Infantil, presente en 33 Establecimientos Penitenciarios.

El programa ha tenido como dificultades, entre otras, la puesta en marcha de los Tribunales de Familia que ha venido a complejizar el ingreso de los niños/as lactantes al programa. Esto es porque, ante la petición expresa de la Administración Penitenciaria, generalmente no se dictan las pertinentes medidas de protección, aduciendo la no competencia del Tribunal. Con ello devienen a lo menos dos grandes problemas, o se excluye derechamente al menor del programa, con el inconveniente para la madre de tener que buscar quien le cuide a su hijo o segundo, se posibilita que se incluya, sin la orden de un juez, quedando ingresado a una cárcel en la más completa ilegalidad.

Por otra parte, si ya el ingreso y la permanencia del menor en la cárcel es traumático, a su egreso este efecto se incrementa considerablemente, no sólo para él, sino también para la madre, que debe entregarlo o a un familiar responsable o al sistema de protección de SENAME. El efecto psicológico de vivir la cárcel, el cambio de ambiente, el desapego abrupto y las condiciones de vida a tan temprana edad, sin duda marcaran una época muy difícil, que dejará huellas duraderas, en su menta tierna. ${ }^{5}$

En la materia, nuestra legislación se ha interpretado de manera errática. A pesar de que la medida cautelar a que se encuentran afectos estos menores, es una de aquellas señaladas en el artículo 70 de la Ley $\mathrm{N}^{\mathrm{o}} 19.968$, se ha obviado permanentemente la 
necesidad que siempre sea impuesta por el competente Tribunal y con la prohibición que en ningún caso se ordene el ingreso de este niño o niña a un establecimiento penitenciario para adultos. De ello se sigue la dificultad de legitimar que alguna de estas medidas pueda ser cumplida en las Residencias Transitorias que administra Gendarmería de Chile al interior de los recintos penales, pues se contraría abiertamente la letra de la ley.

Para legitimar la estadía de un menor lactante, menor de dos años, al interior de un recinto penitenciario, no basta esgrimir la letra del art. 19 del Decreto Supremo No 518 de 1998, sobre Reglamento de Establecimientos Penitenciarios, ${ }^{6}$ ni lo expresado en el respectivo Contrato de Concesión, como allí se indica, por cuanto tales instrumentos sólo intentan satisfacer una necesidad contingente y no se condicen con la verdadera política pública, que en esta materia aconsejan los postulados de nuestro Estado de Derecho.

En efecto, es alarmante la línea en que avanza la norma reglamentaria, no sólo por lo descrito precedentemente, sino además porque en la hipótesis del art. 100 del Decreto Supremo ${ }^{\circ}$ 1.378 de 2007, que establece el Reglamento de la Ley $\mathrm{N}^{\mathrm{o}} 20.084$ de 2005, sobre Responsabilidad Penal Adolescente, en relación al art. 56 de la referida Ley $\mathrm{N}^{\mathrm{0}} 20.084$, se permitiría, en determinadas circunstancias, mantener en un recinto penal, un sistema de atención para niños hasta los seis años de edad.

Para lograr un desarrollo armónico y humano de nuestra sociedad es imperioso que nos ocupemos de nuestros niños, cuidándonos de caer ante el falso resplandor de políticas miopes, que anteponen intereses falaces a los verdaderos imperativos que guían al Derecho en un Estado como el nuestro. 


\section{Notas}

1 Encuesta realizada el año 2005 por UNICRIM, de Gendarmería de Chile.

2 Datos Departamento de Readaptación de Gendarmería de Chile.

3 El artículo 3 en relación al artículo 29 de la Ley $\mathrm{N}^{\circ} 20.032$, que establece un sistema de atención a la niñez y la adolescencia a través de la red de colaboradores del SENAME, posibilita conceder una subvención para la administración de las Residencias, conforme parámetros objetivos que delimita las categorías de cada criterio y los valores de los factores asociados.

4 Servicio Público dependiente del Ministerio de Justicia, que tiene por finalidad atender, vigilar y rehabilitar a las personas que por resolución de autoridades competentes, fueren detenidas o privadas de libertad y cumplir las demás funciones que le señale la ley. Art. $1^{\circ}$ Decreto Ley N².859 de 1979.

5 "La satisfacción de las necesidades de afecto, seguridad y estímulo en los primeros años de vida, cuando el cerebro evoluciona más rápidamente, es fundamental para la formación del perfil intelectual y emocional de cada niño.

El seguimiento de la evolución de grupos de niños demuestra que las experiencias negativas vividas desde el nacimiento hasta el inicio de la escolaridad -período en que los niños son especialmente dependientes de padres y adultos en general- pueden tener como consecuencia serios problemas en al vida adulta.

El desafío para los padres, los educadores y la sociedad en general ante los grandes cambios culturales de las últimas décadas es encontrar espacios estimulantes que permitan al bebé el desarrollo óptimo de sus capacidades. "El pensamiento del bebé." Ann y Richard Barnet. Ediciones B Argentina S.A. 2005, para el sello Javier Vergara Editor.

6 Los establecimientos penitenciarios destinados a la atención de mujeres se denominan Centros Penitenciarios Femeninos (C.P.F.) y en ellos existirán dependencias que contarán con espacios y condiciones adecuadas para el cuidado y tratamiento pre y postnatal, así como para la atención de hijos lactantes de las internas.

En aquellos lugares en que no existan estos Centros, las internas permanecerán en dependencias separadas del resto de la población penal, sin perjuicio de que se incorporen a actividades conjuntas con la población penal masculina.

Toda vez que ingrese una interna con hijos lactantes, el Jefe del Establecimiento deberá comunicar de inmediato este hecho al Servicio Nacional de Menores para los efectos de la respectiva subvención y de los programas o medidas que dicha Institución deberá desarrollar para el adecuado cuidado de los niños. 
En los establecimientos en que se dé un contrato de concesiones, se estará además a lo que este establezca el respectivo contrato respecto del cuidado, residencia y atención del lactante." Art. 19 Decreto Supremo N 518 de 1998. 